\title{
Cognitive analysis and choice of an enterprise's strategic goals
}

\section{Robert A. Karayev}

E-mail: karayevr@rambler.ru

Institute of Control Systems, Azerbaijan National Academy of Sciences

Address: 9, B. Vahabzade Street, Baku AZ1141, Azerbaijan

\begin{abstract}
One of the most crucial and vulnerable stages of strategic management is the cognitive stage associated with the transformation of the strategic vision and of the enterprise's mission into its strategic goals. At this stage, management is faced with the problem of developing a coordinated collective opinion on the content of the goals being formed and with the problem of objective assessment of their effectiveness. The difficulties here are due to the phenomenological features of the stage, such as the informal nature of the transformation procedure, the multi-criteria nature of goals, numerous uncertainties and risks exacerbated by the increased variability of business environments, cognitive barriers caused by linguistic discrepancies and differences in the professional experience of strategy developers. Such features of the stage ultimately lead to ambiguous decisions regarding the content of goals and ambiguous assessments of their effectiveness. In these circumstances, traditional support tools (numerous versions of expert methods, brainstorming, Norton and Kaplan's BSC, SMART technology, etc.) face serious limitations. This paper proposes a cognitive technology for forming a coordinated set of the enterprise's business goals that to a large extent takes into account the features of the given stage. The technology is a single procedure integrating the capabilities of traditional support tools and expanding the creative potential of support based on psychosemantic models and nonmetric multidimensional scaling methods. The results of a real study conducted at a number of enterprises show that cognitive technologies open up new prospects for goal analysis. They can serve as a useful complement to existing support tools and contribute to the design of more effective and realistic business strategies.
\end{abstract}




\section{Graphical abstract}

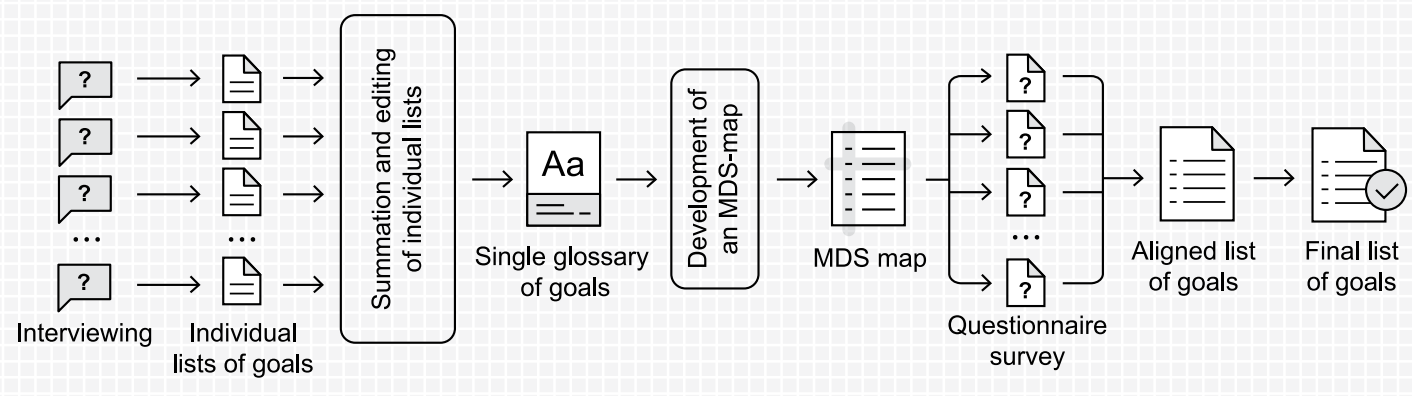

Key words: strategic goals; analysis and choice technology; cognitive approach.

Citation: Karayev R.A. (2019) Cognitive analysis and choice of an enterprise's strategic goals.

Business Informatics, vol. 13, no 4, pp. 28-38. DOI: 10.17323/1998-0663.2019.4.28.38

\section{Introduction}

$\mathrm{T}$ The problem of forming an enterprise's strategic goals (hereinafter referred to as "the goals") is one of the critical problems of strategic management [1-3]. The success of a strategic project largely depends on its solution. The complex, informal, heuristic nature of the problem has long been at the root of the issue of creating effective support tools that adequately reflect the phenomenology of the problem itself, the accumulated positive experience of using traditional support tools, as well as new features of modern intelligent technologies.

In the following sections, we list the most popular support tools, giving a brief critical analysis of these tools. Based on the results of our analysis, the basic principles that can be used as the foundation for an improved support technology are formulated, and the prospects of the cognitive approach in this context are substantiated. We consider the challenges of the implementation of the cognitive approach and ways to overcome them by means of models of experimental psychosemantics.
The basic principles, the diagram and operation algorithms of the proposed support technology are provided. A demonstration example of its use is provided and the possibilities and prospects of its application are discussed.

\section{Brief description of the traditional methods}

The most popular support tools currently used in strategic management in the selection of an enterprise's strategic goals include expert methods (survey, interviewing, Delphi method), brainstorming, SMART technology, and Norton and Kaplan's strategic cards (BSC).

Expert methods [4]. The conceptual basis of these methods is the "general evaluation scheme" proposed in [4]:

$$
\mathrm{E}=<\Omega, \Omega \mathrm{e}, \mathrm{L}, \mathrm{Q}, \varphi>,
$$

where $\Omega-$ the initial set of permissible goal assessments according to the accepted criterion;

$\Omega e$ - the set of the permissible goal assessments made by various experts $(\Omega \mathrm{e} \subseteq \Omega$ );

$\mathrm{L}-$ the rules of interaction between experts; 
$\mathrm{Q}$ - evaluation feedback;

$\varphi$ - the method for processing the assessments of various experts in order to determine the resulting assessment.

The expert methods widely used to formulate goals are, in fact, various modifications of this general scheme.

Brainstorming technique [5]. The once widely advertised "brainstorming" method was regarded as a way of "enhancing" the creative capabilities of a team of analysts in solving ill-structured problems. This is a group creativity technique by which efforts are made to find a conclusion for a specific problem by gathering a list of ideas spontaneously contributed by its members.

SMART technology [6]. This is a declarative approach that positions selected goals according to the following criteria: specific (S), measurable (M), achievable (A), relevant (R), time bound (T).

BSC strategic cards (balanced scorecards) [7]. The BSC concept proposed by Kaplan and Norton involves a hierarchical structuring of an enterprise's performance. The balanced scorecard system uses strategy at four interconnected levels - the financial level, customer level, process level, and learning and growth level. This structuring focuses on groups of goals, allowing one to deal with the well-known "dimensionality problem" [7]. Here, the number of goals in each of the layers is usually taken as equal to 5-7, which is associated with limited human psychophysiological capabilities [8].

\section{Critical analysis of the traditional methods}

An analysis of the aforementioned methods and the practice of their application allows us to formulate a number of significant limitations that arise in their practical use and to lay out the main ways to improve the support procedure.

As noted above, the primary task to be solved at the cognitive stage is forming the set of goals. They can be established by:
1) survey method [9], using a set of goals predetermined by experts;

2) interviewing method [10], when experts offer their own individual opinion regarding the set of goals;

3) Delphi method [11], which is a group survey technique. The procedures used in the Delphi method are characterized by three key features: anonymity, regulated feedback and group response. Feedback is provided through several survey rounds, with the results of each round being processed by statistical methods and communicated to the experts. In the second and subsequent rounds, experts argue their answers. Thus, in subsequent rounds, experts can revise their initial answers. From round to round, experts' answers become increasingly stable until they stop changing, which stops the survey. Practice shows that three or four survey rounds are usually conducted, since the estimates no longer change after that.

The common feature of these expert methods is that they are questionnaire-based. The difference is that their implementation can be carried out in closed form (experts are offered ready questionnaires) or in open form (experts form questionnaires themselves and fill them in during the interview process). Depending on the form of questionnaires, various difficulties may arise. Thus, the use of an open form can result in different sets of goals being proposed by each expert and an ambiguous interpretation of goals, since the same goals can be referred to by different experts in different terms, or goals with the same name can have different semantics and pragmatics. Using a closed form of questionnaires can significantly limit experts' ability to express their opinions on a set of goals and their verbal wording.

This problem is most clearly manifested in another popular method, the "brainstorming" technique. Even in the early days of this method, publications appeared that cast doubt on its effectiveness in generating ideas [12]. Studies of the brainstorming technique revealed three groups of processes that reduce its effectiveness [13]: 
$\downarrow$ social loafing, which allows managers to hide behind the backs of colleagues;

$\downarrow$ evaluation apprehension - the fear of being judged by colleagues for possibly "silly" ideas;

$\checkmark$ production blocking due to lowered criticality, since according to the technique, any member of the group can support any idea at any time.

Studies over the past decade show that individual methods of goal generation are still more effective than collective ones [14].

Among the support tools, the BSC approach deserves special attention. In addition to highlighting an enterprise's goals, the structural organization of this approach involves setting their mutual influences both within each of the layers and between the layers. For instance, the staff of an enterprise, even given ideal quality of its employees, can achieve results in customer relations only if the business processes of management are properly organized (the influence of the goals of the "business processes" layer on the goals of the "customer" layer). Properly organized (efficient and rational) business processes makes it possible to achieve maximum performance defined in the customer layer (market share, service satisfaction), which, in turn, allows one to achieve the desired financial results.

However, the BSC approach is only attractive up to the moment the management encounters the question: where can we get the necessary and sufficient set of business goals for a specific enterprise? Obviously, the answer here is unambiguous: only from the heads of the managers developing the strategy of the enterprise. However, the task of explicating this knowledge and its practical use is far from trivial. Its simplicity without the use of special support tools is illusory and deceptive.

\section{Cognitive technology for generating and analyzing goals}

\subsection{Key principles}

The considerations set out above allow us to formulate the key principles that can form the basis of an improved goal formation technology. First, the technology should be based on an individual rather than a group method of evaluation. Second, the technology should provide tools for solving the inevitable problem associated with the explication of managers' internal representations, analysis and coordination of their individual representations and the formation of a single collective opinion. The peculiarity of this problem lies in the fact that the explication procedure is informal, while the goal assessments themselves are multi-criteria (SMART technology, for instance, sets goals according to five criteria) and often non-metric (qualitative, linguistic) in nature, which excludes the possibility of quantitative processing of the source expert material.

Attempts have been made for a long time to use the cognitive approach to solve this type of problems [15-17].

One of the central points of the cognitive approach is the assertion that individual human behavior which is formed in response to external stimuli is determined by the structure of a person's representations in the subject area to which a specific external stimulus belongs. Such structures of human internal representations are called "mental models" [18]. Mental models are internal representations of causal relationships within a system, allowing a person to understand, predict and solve practical problems associated with this system. Mental models are based on human experience and expectations. They control our behavior in various situations and are dynamic constructs that change under the influence of learning, new information or a person's state. A person can mentally manipulate mental models, "starting" them in the form of an internal experiment and evaluating its results under different conditions and a different sequence of steps that form such a model. The described manipulations are the internal basis for the formation of all the main components of an enterprise's strategy. 
Thus, managers have internal, mental models of competition [19], and entrepreneurs have mental models of the industry [20]. Both of these mental models help to assess the current situation and make justified decisions.

However, the use of the cognitive approach in the formation of goals is complicated for a number of reasons. The main such reasons are the following.

First, all of an enterprise's goals are products of managers' thoughts, sitting in their heads in the form of metal models and should be extracted in the clearest form possible. However, the form of human internal representations hinders the solution of this problem. "Brain languages" [21], "non-disjunctive" human logic [22] cannot be directly translated by means of the traditional disjunctive means of modern mathematics.

Secondly, the complexity of translation is compounded by the fact that an enterprise's goals are the product of thinking of many people - the enterprise's owner, and top and middle management involved in the strategy development. This results in the problem of coordinating many goals and moving from individual mental models to collective, team knowledge.

Third, the difficulties of application of the cognitive approach are also due to the fact that the possibilities of this approach are limited by human psychophysiological capabilities [23].

Accordingly, the number of goals included in the task of goal analysis should be limited by these capabilities. On the other hand, the set of goals being analyzed should cover almost all aspects of an enterprise's operation. The BSC approach is best suited to solve the "dimensionality problem" that arises in this case. However, the aforementioned difficulties of explication impose serious limitations on its practical use. The issue of reasonable detailing of the problem field and the issue of reduction of goals by excluding less significant goals from consideration become unavoidable here.
Our analysis has shown that the listed difficulties of applying the cognitive approach are surmountable. Models of experimental psychosemantics open up broad prospects for overcoming these difficulties [24, 25]. In recent years, models of experimental psychosemantics find increasingly wide application in social and economic research.

Experimental psychosemantics is an area of cognitive science that studies various forms of representing objects of the world in the individual human consciousness (images, symbols, verbal forms). The main method of experimental psychosemantics is the construction of socalled "subjective semantic spaces" (an individual's model representations of objects of the world) by nonmetric multi-dimensional scaling [26-28]. This is a method of making subjective assessments when the subject (expert) is asked to evaluate an object by a set of attributes, using scales based on verbal gradations. Scaling in this context differs from a single measurement in that it allows for individual observations to recreate a holistic image of the analyzed object. An important advantage of the method is that it allows us to identify the presence of different points of view on the object being analyzed by experts and to coordinate their opinions on the syntactic and semantic levels. At the same time, differences between expert assessments are not considered experimental errors but are important in themselves.

The use of psychosemantic models provides an important advantage. It makes it possible to apply a mixed approach to the formation of goals, which effectively combines the positive aspects of the interviewing method (that maximizes the goal searching space), the survey method (that involves describing goals in common terms), SMART technology (that takes into account the multi-criteria nature of goals) and the BSC concept (that structures the problem field of target analysis).

Our technology for generating and analyzing goals takes into account these key points. 
In the following paragraphs, we give a general description of the technology and a demonstration of its practical application. The possibilities and prospects of the cognitive selection of goals are discussed below.

\subsection{The diagram of the technology}

The block diagram of the technology presented in Figure 1 shows the sequence of steps that implement the process of analysis and formation of goals.

\subsection{Goal alignment method}

The goals alignment method is based on remote nonmetric multidimensional scaling models based on the Euclidean metric [27, 28] that meet the conditions of the problem we are investigating. The goal alignment diagram in this case is as follows:

$$
\mathbf{C}=<\mathbf{I}, \mathbf{P}, \mathbf{Z}, \mathbf{E}, \varphi>,
$$

where $\mathbf{I}$ - the name of the goal;
$\mathbf{P}$ - the set of attributes (dimensions) of the goal;

$\mathbf{Z}$ - the nonmetric attribute assessment scales;

$\mathbf{E}$ - the individual goal assessments for each of the attributes made by various experts;

$\varphi-$ MDS algorithm for processing individual assessments and determining the degree of consistency of goals.

The algorithm of the method can be demonstrated through the following example.

Assume we have a questionnaire card (MDS map), which is (for clarity and simplicity of presentation) a matrix of two-dimensional scaling of goals by the attributes: "Significance of the business goal" and "Attainability of the business goal" from the management's point of view. Each of the attributes is evaluated on a linguistic scale: "high," "medium," "low." Assume also that the number of experts is $M$. Each of the experts places goals from the single glossary of goals (SGG) in a cell of the matrix in accordance with his or her ideas about the significance and attainability of the goal. Obvi-

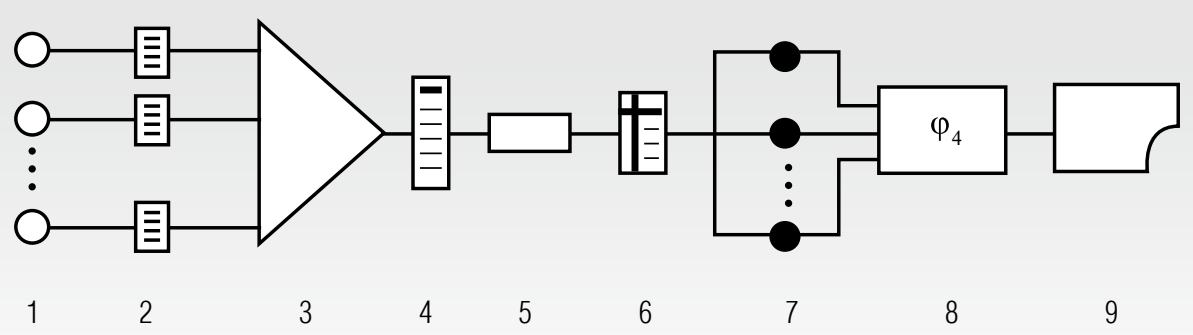

1 - interviewing experts (open survey);

2 - individual lists of goals (ILG) received from various experts;

3 - simple summation of individual lists and their editing;

4 - a single glossary of enterprise goals (SGG);

5 - development of an MDS (multidimensional scaling) map multidimensional matrix of goal assessment criteria [26, 27];

6 - MDS map;

7 - questionnaire survey of experts (closed survey) based on the SGG;

8 - processing of the results of the questionnaire survey by MDS methods, ranking and selection of the aligned list of goals (ALG);

9 - final list of goals ( $F L G)$

Fig. 1. The block diagram of the technology of data generating and analysis 
ously, some cells of the matrix can end up with several goals and some cells without a single one. Denote by $m_{i j}$ the number of experts who placed the same goal in the cell $(i, j)$. It is clear that $\sum m_{i j}=M$.

After each of the experts has filled the matrix, the aggregation of the obtained assessments is carried out. To this end, each cell is assigned with respect to each target $(c \in C)$ a weight $\lambda_{i j}^{c}=m_{i j} / M, \lambda_{i j}^{c}=[0,1]$, which, in fact, is a two-dimensional function of the distribution density of expert opinions. To take into account the misalignment of opinions, a measure called the coefficient of inconsistency $\left(K^{c}\right)$ is introduced, which characterizes the degree of inconsistency of the management's opinions regarding this goal $c$.

If the opinions of the experts regarding the goal $c$ coincided and they filled, for instance, cell $(2,3)$, then the coefficient $K^{c}$ would be equal to zero, and the coordinates of this opinion would be equal to $(2,3)$. But since the experts' opinions are scattered across the matrix, in order to assess the degree of inconsistency, it is necessary to find the mean abscissa $I^{c}$, the mean ordinate $J^{c}$ and the coefficient of inconsistency $K^{c}$. Since the function of the distribution density of opinions has already been determined, these values are calculated from the following formulas:

Mean inconsistency abscissa:

$$
I^{c}=\sum_{i j} \lambda_{i j}^{c} \cdot i
$$

Mean inconsistency ordinate: ;

$$
J^{c}=\sum_{i j} \lambda_{i j}^{c} \cdot j
$$

Inconsistency coefficient:

$$
K^{c}=\sum_{i j} \lambda_{i j}^{c} \cdot \sqrt{(i-I)^{2}+(j-J)^{2}} .
$$

\subsection{Rules of goal ranking}

The following rules of goal ranking can be established on the basis of the coefficient $K^{c}$.
Rule 1. If $K^{c}<0.5$ then the degree of inconsistency of the management's views on the goal $c$ is low and the goal $\mathrm{c}$ can be included in the FLG;

Rule 2. If $K^{c}=[0.5 ; 0.75]$ then we have an uncertainty and further elaboration is required regarding the inclusion of the goal $c$ in the FLG;

Rule 3. If $K^{c}>0.75$ then the degree of inconsistency of opinions on this goal is high and the goal cannot be included in the FLG (the management does not perceive this goal as a goal and will actually exclude it from the strategy in any case).

\section{Technology application example}

The technology presented has been used in a number of real-life projects. Table 1 shows the results of the application of the technology to the selection of business goals for a poultry enterprise at an agricultural holding in Baku. The following business goals of the enterprise were considered (the appropriate inconsistency coefficients $K^{c}$ are presented in the parenthesis):

1. Increasing production of broilers to 4500 tons per year, and of hatching eggs - to 10 million pes per year $\left(K^{c}=0.3\right)$;

2. Raising the market share of the enterprise in 2013-2017 in the domestic market to $15 \%$ $\left(K^{c}=0.32\right)$;

3. Achieving annual sales of up to 17.5 million $\operatorname{AZN}\left(K^{c}=0.33\right)$;

4. Implementing a new marketing strategy and creating a wide marketing chain $\left(K^{c}=0.58\right)$;

5 . Further training of production personnel $\left(K^{c}=0.32\right)$;

6. Modernization of technological equipment $\left(K^{c}=0.59\right)$;

7. Using new productive breeds of poultry $\left(K^{c}=0.69\right)$; 
8. Involving international strategic management experts $\left(K^{c}=0.53\right)$;

9. Development and introduction of new feeding diets $\left(K^{c}=0.67\right)$.

Notation in the table: $\mathrm{X}(\mathrm{Y})$, where $\mathrm{X}$ is the goal number, $\mathrm{Y}$ is the number of experts who placed the goal in the appropriate cell.

The table shows that testing the single glossary of goals made it possible, based on the analysis of the coefficients $K^{c}$, to reveal the existence of a consistent opinion regarding only a portion of the goals ( 4 out of 9 ). These are goals 1 , 2, 3 and 5: they all have values of the inconsistency coefficient $K^{c}$ from 0.3 to 0.33 , and this allows us to consider inconsistency of the managers' opinions as low. On the other hand, the management cannot make a decision on the remaining goals, regarding either their significance or the possibility of achieving them. This means either that their inclusion in the business strategy is ineffective or that the goal analysis procedure requires an additional iteration.

\section{Discussion}

\subsection{Inconsistency of the managers' opinions}

The practice of applying the proposed technology has shown that different outcomes are possible when assessing the degree of incon- sistency of management's opinions:

1) management's opinions are completely inconsistent (the assessment of inconsistency is high, and it is impossible to distinguish groups of managers with close opinions). In this case, the results of the evaluation are obviously not suitable for decision-making. Depending on the specific situation, one should either consider the evaluation unsuccessful and choose not to conduct the study, or conduct a second evaluation. Re-evaluation should account for the possible reasons of the failure, such as, e.g. the goals were incorrectly formulated, the goal assessment scales were selected poorly, it was impossible to create the right psychological and material environment, the managers have hidden personal and group interests, etc.;

2) managers' assessments are divided into several groups, within each the consistency is quite high, but it is low in the whole by the team of managers. Therefore, it is logical to assume that this is a case of different methodological approaches or different social groups. In this case, managers' opinions cannot always be brought to consistency among themselves even through a lengthy discussion. Therefore, it is advisable to supply the decision maker with several group assessments with appropriate comments;

3) group assessment is highly consistent. Such

Table 1.

Assessment and ranking of business goals of a poultry enterprise

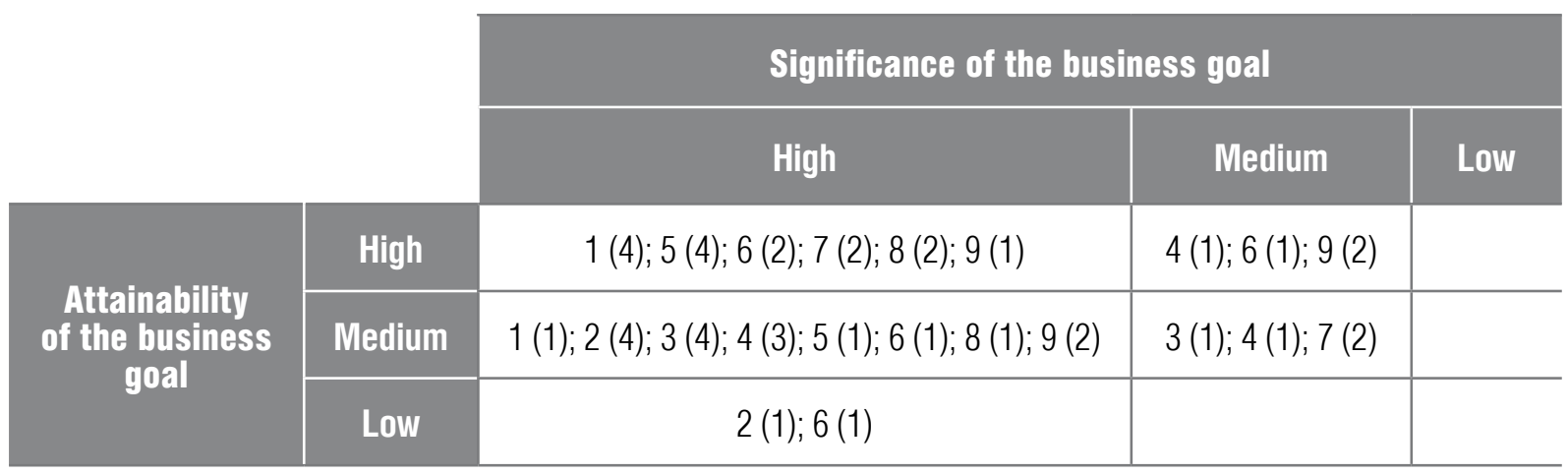


an assessment can be presented to the decision maker, but in any case, it makes sense to analyze the presence of extreme opinions (to find out what percentage of managers have them, how they substantiate their points of view, what the assessment of inconsistency will be if they are not taken into account).

Thus, the situations that management faces when forming a set of goals for an enterprise are quite diverse. Therefore, depending on the specific situation, the support technology described above can be supplemented by all available sources of theoretical and reference information for calculations and additional analysis.

\subsection{Goal selection}

The problem field of the goal selection problem is very large. It will suffice to look at the structure of the BSC card to know that it is almost impossible to solve the problem. Here strategy developers are confronted with the "dimensionality problem," the inevitable companion of all complex projects. To solve the problem within the ideology of the cognitive approach, the "camera metaphor" was proposed [29], in which a "camera" glides across the "picture of the world" and, by the operator's will, selectively captures fragments of this world, zooming in and out on a fragment of interest. This metaphor is certainly productive, but it must be supplemented by a very important circumstance. When exploring a fragment of the world, the analyst and only the analyst alone can exercise intuitive control of the entire problem field as a whole, investigating all aspects of the problem and understanding how they relate to the problem being solved within the context of the selected fragment. This circumstance is fundamental and it indicates that the cognitive approach should be interactive in nature and it is incorrect to use it as a local computer program, as is the case in expert systems [30] and in numerous studies on cognitive modeling ${ }^{1}$.

Cognitive models should be used as a research tool and be open to contextual analysis by human beings.

\subsection{BSC layers}

The proposed goal selection technology can be carried out for all four layers of the balanced scorecard (BSC). However, solving each separate local problem, managers must monitor changes in its parameters in the context of possible changes in other "related" fragments of the problem field.

\subsection{Context analysis}

Today, in the growing complexity of economic relations, it is customary to talk about the increasing role of context [31]. Contextual analysis in the process of goal formation is the challenge and requirement of today's management practice. The ability to correctly take into account the context based on the knowledge of cognitive technologies places increased demands not only on the basic training of managers, but also on their intuition. If mastering the technologies of cognitive analysis puts forward special tests for the professional training of strategy developers, then the ability to "embed" these technologies in a specific context requires well-developed intuition. This is already a new quality expected from strategy developers which is difficult to achieve on the basis of the traditional training system. This essentially refers to the recently discussed issue of revising business education programs.

\section{Conclusion}

Practice shows that when developing management strategies, the stage of the transition from the strategic vision and mission of the

1 International Conference on Cognitive Modelling (https://iccm-conference.github.io/previous.html) 
enterprise to the formulation of its business goals is often the most vulnerable one from the point of view of loss of effectiveness.

The greatest difficulties here are due to the transition from the individual opinions of top managers to a coordinated (team) opinion.

This strategic management issue currently does not have sufficiently effective support tools. The support technology proposed in this paper, based on psychosemantic models and the nonmetric multidimensional scaling method, implements an end-to-end procedure for objec- tivizing management's subjective opinions on the enterprise's goals and makes it possible to move from individual knowledge to coordinated team knowledge. In real conditions (insufficient and varied practical experience, insufficiently high qualifications, conflicting opinions, personal and group interests), the technology can serve as a tool to complement well-known support tools and, consequently, be very useful for the appropriate selection of an enterprise's development strategy in complex modern economic conditions.

\section{References}

1. Drucker P.F. (2001) Management challenges for the 21st century. N.Y.: Harper Business.

2. Kleiner G.B. (2008) Enterprise strategy. Moscow: Delo (in Russian).

3. Isaev D.V. (2008) The Rational model of strategic management. Financial Weekly, no 25, pp. 14-15; no 26, p. 12 (in Russian).

4. Makarov I.M., Vinogradskaya T.M., Rubchinsky A.A., Sokolov V.B. (1982) Theory of choice and decision making. Moscow: Nauka (in Russian).

5. Leskov S.L. (2012) Brainstorming. Moscow: MSU (in Russian).

6. Bogue R.L. (2005) Use S.M.A.R.T. goals to launch management by objectives plan. Available at: https://www.techrepublic.com/article/use-smart-goals-to-launch-management-by-objectives-plan/ (accessed 20 November 2013).

7. Kaplan R.S., Norton D.P. (1996). The balanced scorecard: Translating strategy into action. Boston: Harvard Business School Press.

8. Miller G. (1955) The magical number seven, plus or minus two: Some limits on our capacity for processing information. Psychological Review, vol. 101, no 2, pp. 343-352.

9. Walsh J. (1988) Selectivity and selective perception: An investigation of managers' belief structures and information processing. Academy of Management Journal, vol. 31, no 4, pp. 873-893. DOI: $10.5465 / 256343$.

10. Markiczy L., Goldberg J. (1995) A method for eliciting and comparing causal maps. Journal of Management, vol. 21, no 2, pp. 305-333. DOI: 10.1177/014920639502100207.

11. Loo R. (2002) The Delphi method: a powerful tool for strategic management. Policing: An International Journal of Police Strategies \& Management, vol. 25, no 4, pp. 762-769. DOI: $10.1108 / 13639510210450677$.

12. Isaksen S.G. (1988) A review of brainstorming research: Six critical issues for inquiry. Available at: https://www.semanticscholar.org/paper/A-Review-of-Brainstorming-Research\%3A-Six-CriticalIsaksen/4abc961cb62e8b230f9683125e984eec3550caa4 (accessed 22 June 2016).

13. Furnham A. (2000) The brainstorming myth. Business Strategy Review, vol. 11, no 4, pp. 21-28. DOI: $10.1111 / 1467-8616.00154$.

14. Paulus P., Dzindolet M. (1993) Social influence processes in group brainstorming. Journal Personality and Social Psychology, vol. 64, no 4, pp. 575-586. DOI: 10.1037/0022-3514.64.4.575.

15. Schwenk C.R. (1988) The cognitive perspective on strategic decision making. Journal of Management Studies, vol. 25, no 1, pp. 41-55. DOI: 10.1111/j.1467-6486.1988.tb00021.x. 
16. Narayanan V.K., Zane L.K., Kemmerer B. (2011) The cognitive perspective in strategy: An integrative review. Journal of Management, vol. 37, no 1, pp. 305-323. DOI: 10.1177/0149206310383986.

17. Karayev R.A. (2015) Cognitive approach and its application to the modeling of strategic management of enterprises. Knowledge engineering: Principles, methods and applications (Ed. Alfonso Perez Gama). N.Y.: Nova Science, pp. 79-101.

18. Johnson-Laird P.N. (1980) Mental models in cognitive science. Cognitive Science, vol. 4, no 1, pp. 71-115. DOI: 10.1207/s15516709 $\operatorname{cog} 0401 \_4$.

19. Johnson P., Daniels K., Asch R. (1998) Mental models of competition. Managerial and organizational cognition: Theory, methods and research (Eds. C. Eden, J.-C. Spender). London: SAGE Publishing, pp. 130-146.

20. Gary M.S., Prietula M.J., Feltovich P. (2017) Mental models as the interface between the business environment and strategic decisions. Academy of Management Proceedings, no 1. DOI: 10.5465/ AMBPP.2017.14588abstract.

21. Pribram K.H. (1971) Languages of the brain. Experimental paradoxes and principles in neuropsychology. Englewood Cliffs, N.J.: Prentice-Hall.

22. Brushlinsky A.V. (1979) Thinking and prediction. Moscow: Myisl (in Russian).

23. Bays P.M., Husain M. (2008) Dynamic shifts of limited working memory resources in human vision. Science, vol. 321, no 5890, pp. 851-854. DOI: 10.1126/science.1158023.

24. Petrenko V.F. (2005) The basics of psychosemantics. Saint-Petersburg: Piter (in Russian).

25. Petrenko V.F. (2013) Multidimensional consciousness: A psychosemantic paradigm. Moscow: Eksmo (in Russian).

26. Young F.W. (1970) Nonmetric multidimensional scaling: Recovery of metric information. Psychometrica, vol. 35, no 4, pp. 455-473.

27. Green P.E., Carmone F.J., Smith S.M. (1989) Multidimensional scaling: Concepts and applications. London: Allyn and Bacon.

28. Tolstova Yu.N. (2006) Basics of multidimensional scaling. Moscow: University (in Russian).

29. Mintzberg H., Lampel J., Ahlstrand B. (2005) Strategy safari: A guide tour through the wilds of strategic management. N.Y.: Free Press.

30. Waterman D.A. (1986) Guide on expert systems. Reading, MA: Addison-Wesley.

31. Balatsky E. (2006) The dialectic of cognition and the new paradigm of economic science. World Economy and International Relations, no 7 (in Russian).

\section{About the author}

\section{Robert A. Karayev}

Dr. Sci. (Tech.);

Professor, Head of Ecosystems Modeling Laboratory,

Institute of Control Systems, Azerbaijan National Academy of Sciences,

9, B. Vahabzade Street, Baku AZ1141, Azerbaijan;

E-mail: karayevr@rambler.ru 